\title{
Oligella urethralis isolada em hemocultura de paciente internada no complexo HSP/UNIFESP
}

Oligella urethralis isolated in hemoculture from patient interned in HSP-UNIFESP complex

Luis Gustavo Raimundo'; Leandro Dinato²; Fernando Pereira Pinto ${ }^{3}$; Antonia Maria de Oliveira Machado ${ }^{4}$

\section{unitermos}

Oligella urethralis

Hemocultura

Phoenix

Linfoma

\section{resumo}

Primeiro isolado de Oligella urethralis em duas amostras de sangue periférico detectado por metodologia de monitoração contínua de metabolismo (sistema Bactec $^{\circledR}$ ) e identificado pelo sistema automatizado Phoenix ${ }^{\circledast}$ (BD System) em paciente com linfoma retroperitoneal com metástase em sistema nervoso central (SNC) no Hospital São Paulo da Universidade Federal de São Paulo (HSP/UNIFESP).

\section{abstract}

First time isolation of Oligella urethralis in two samples of peripheral blood detected by continuous metabolism monitoring methodology (Bactec 61650 system) and identified by the automatized Phoenix 61650 system (BD System) in patient with retro-peritoneal lymphoma with metastasis in the central nervous system at São Paulo hospital of Federal University of São Paulo (HSP/UNIFESP). key words

oligella urethralis

Hemoculture

Phoenix

Lymphoma

1. Graduado em Medicina; médico residente em Patologia Clínica/Medicina Laboratorial do Hospital São Paulo/UNIFESP.

2. Médico residente em Patologia Clínica do Hospital São Paulo/UNIFESP.

3. Graduado em Biologia; microbiologista do Hospital São Paulo/UNIFESP.

4. Doutora em Medicina; diretora técnica do Laboratório Central do Hospital São Paulo/UNIFESP. 


\section{Introdução}

Previamente a 0 . urethralis estava incluída no gênero Moraxella como M. urethralis. Em 1987 descreveu-se pela primeira vez um novo gênero com o nome de Oligella. Tratase de uma bactéria exigente do ponto de vista nutricional. $\mathrm{Na}$ atualidade, o gênero apresenta apenas duas espécies: 0 . urethralis e 0 . ureolytica(1).

Entre as reações características para O. urethralis temos: motilidade negativa, DNAse negativa, indol negativo, catalase e oxidase positivas, além de não ser capaz de hidrolisar esculina e ureia ${ }^{(2)}$.

A Oligella urethralis é um cocobacilo gram-negativo aeróbico. O gênero Oligella é distinto dos gêneros Moraxella e Neisseria, no entanto divide relações genéticas e fenotípicas com os gêneros Alcaligenes, Bordetella e Taylorella. A O. urethralis é um organismo comensal do trato genitourinário com baixo grau de patogenicidade, ocorrendo principalmente em pacientes imunocomprometidos, sendo raramente responsável por infecções invasivas, como artrite séptica, septicemia e peritonites ${ }^{(3)}$.

\section{Relato de caso}

Paciente M. V. L., 69 anos, apresentou diagnóstico de neoplasia invasiva de sistema nervoso central (SNC) em fevereiro de 2008 e foi internada, depois de um mês, com queixa de dor abdominal, febre e síndrome colestática. Ao exame de entrada a paciente encontrava-se em choque séptico e necessitou de medidas invasivas para recuperar a estabilidade clínica. Foram colhidas culturas na admissão. A paciente apresentou evolução favorável inicial, com extubação e estabilidade hemodinâmica.

Foi isolada, em duas amostras de sangue periférico (hemocultura de admissão) por metodologia de monitoração contínua de metabolismo pelo sistema Bactec ${ }^{\circledR}$, uma cepa que foi identificada como Oligella urethralis pelo sistema automatizado Phoenix ${ }^{\circledast}$ (BD System). A paciente respondeu rapidamente ao esquema empírico inicial com ciprofloxacino e metronidazol. Cefepima foi introduzida empiricamente um dia após a admissão, mantendo-se também o esquema inicial, pois a paciente apresentava internação prévia recente (ocasião da descoberta da neoplasia de SNC). As concentrações inibitórias mínimas (MICs) das seguintes drogas foram obtidas também por meio do aparelho Phoenix: cefepima MIC: $>16 \mathrm{mcg} / \mathrm{ml}$; ciprofloxacino MIC: $\leq 0,5 \mathrm{mcg} / \mathrm{ml}$.
A paciente estava em investigação de uma massa abdominal evidenciada aos exames de imagem e apresentou rápida deterioração do status clínico com rebaixamento importante do nível de consciência e evolução para o óbito após 19 dias de internação. Apesar de ter apresentado sinais de sepse pouco antes do óbito, a necropsia sugeriu morte por hipertensão intracraniana devida a proliferação à distância de linfoma retroperitoneal.

\section{Discussão}

Estudos com teste de suscetibilidade denotam que a $\mathrm{O}$. urethralis é geralmente suscetível aos betalactâmicos, porém uma cepa com genes codificadores de betalactamase, com capacidade de hidrolisar carbenicilina, e de cefalosporinase (com identidade genética semelhante às encontradas em Acinetobacter baumanii) já foi isolada a partir do trato genitourinário de uma paciente do sexo feminino com infecção urinária. Neste caso, a cepa apresentava resistência a penicilina e cefalosporinas de pequeno espectro ${ }^{(3)}$.

Hujer et al. sugeriram, em 2005, a partir da comparação de um novo alelo variante de cefalosporinase pertencente a $A$. baumanii, levando em conta a sequência de aminoácidos, que enzimas descritas previamente em $A$. baumanii, Acinetobacter espécie genômica 3 e O. urethralis (da África e Europa) na verdade tratavam-se de integrantes de uma mesma família da classe $\mathrm{C}$ de enzimas ${ }^{(4)}$.

Em 1996, Riley et al. publicaram os primeiros casos de peritonite causados por 0 . urethralis em dois pacientes em programa de diálise peritoneal. Em ambos os casos as cepas isoladas mostraram resistência ao ciprofloxacino, porém mantinham-se sensiveis a um grande espectro de antimicrobianos. Sugeriu-se que poderia se tratar de um germe oportunista e que o uso prolongado de quinolonas nestes pacientes poderia ser fator de pressão seletiva ${ }^{(5)}$.

Em 2006, loakimidou et al. publicaram um caso de septicemia, de provável foco urinário inicial, atribuída à 0 . urethralis em uma paciente com câncer de mama terminal, inclusive com metástase óssea. Assim como neste estudo, a paciente em questão também apresentava doença neoplásica avançada confirmada somente depois da necropsia(2).

Em nosso serviço, no entanto, foi o primeiro caso de isolamento desta espécie, e os serviços de microbiologia devem estar atentos à possibilidade de emergência deste patógeno oportunista. 


\section{Referências}

1. MORA, S. E. et al. Infección urinaria por Oligella urethralis. Aten Primaria, v. 28, p. 622-3, 2001.

2. IOAKIMIDOU, A. et al. Septicemia caused by Oligella urethralis in a patient with end-stage câncer: clinical microbiology. Newsletter, v. 28, n. 4, p. 30-1, 2006.

3. MAMMERI, H. et al. Chromosomal integration of a cephalosporinase gene from Acinetobacter baumannii into Oligella urethralis as a source of acquired resistance to B-lactams. Antimicrob Agents Chemother, v. 47, n. 5, p. 1536-42, 2003.
4. HUJER, K. M. et al. Identification of a new allelic variant of the Acinetobacter baumannii cephalosporinase, ADC-7 beta-lactamase: defining a unique family of class $C$ enzymes. Antimicrob Agents Chemother, v. 49, n. 7, p. 2941-8, 2005.

5. RILEY, U. B. G., et al. Quinolone resistance in Oligella urethralis: associated chronic ambulatory peritoneal dialysis peritonitis. Journal of Infection, v. 32, n. 2, p. 155-6, 1996. 